
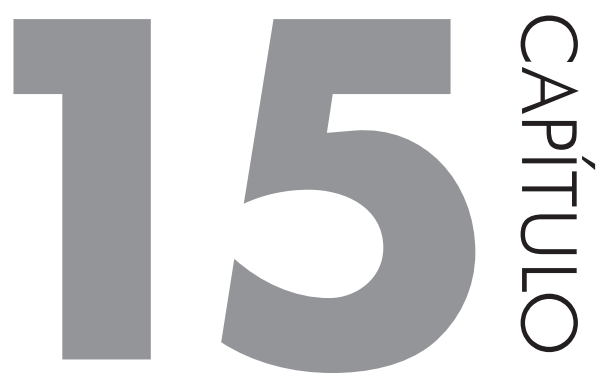

\title{
A PRETÔNICA /O/ NA FALA DE NOVA IGUAÇU/RJ
}

FABIANE DE MELLO VIANNA DA ROCHA ${ }^{1}$

\section{INTRODUÇÃO}

Este artigo expõe parte dos resultados da análise variacionista de Rocha (2013), destacando o comportamento da vogal pretônica /o/ na fala de Nova Iguaçu-RJ. Os dados investigados foram extraídos das entrevistas que constituem as amostras do Projeto Estudo comparado dos padrões de concordância em variedades africanas, brasileiras e europeias. Trata-se de inquéritos, do tipo DID (Diálogo Informante e Documentador), efetuados com dezoito indivíduos naturais do município, distribuídos por sexo, faixa etária e nível de escolaridade. Além desses condicionamentos sociais, controlaram-se, ainda, as seguintes variáveis estruturais: i) qualidade da vogal da sílaba seguinte; ii) nasalidade de /o/; iii) características articulatórias das consoantes adjacentes (modos e pontos de articulação das consoantes precedente e seguinte à vogal pretônica); iv) tipo de sílaba; v) distância entre a vogal estudada e outra alta presente no vocábulo; vi) localização

1 Orientanda da professora Silvia Brandão desde a graduação, por diversas razões, posso dizer que a vida me deu muito mais do que uma orientadora: conheci um ser humano maravilhoso, uma amiga que ultrapassa os limites da academia, a quem serei eternamente grata. 
da pretônica no vocábulo; vii) natureza da atonicidade de /o/; e viii) classe gramatical do vocábulo e itens isolados. ${ }^{2}$ Assim, com o intuito de avaliar influências sociais e estruturais nos processos de alçamento/manutenção de timbre do segmento em questão, sucedendo essa breve introdução, ressaltam-se, na seção adiante, alguns comentários mais gerais sobre o vocalismo pretônico no Português do Brasil (doravante PB) e a Sociolinguística Variacionista (cf. LABOV, 1972, 1994, 2001). A seção 3 descreve os resultados encontrados. Por fim, encerram o estudo, algumas considerações finais sobre os dados e as referências bibliográficas que nortearam a proposta.

\section{PRESSUPOSTOS TEÓRICO-METODOLÓGICOS}

\subsection{O vocalismo pretônico no PB: breves comentários}

Em suas descrições sobre o vocalismo no PB, Camara Jr. (1970) propõe que o número de fonemas vocálicos varia de acordo com a posição do segmento quanto ao acento, atingindo seu limite máximo de distinção na matriz tônica. Segundo o autor, nessa posição, existem sete unidades distintivas que se reduzem, por neutralização, a cinco, quatro e três fonemas nos ambientes pretônico, postônico não final e final, respectivamente.

A neutralização ou anulação de um ou mais traços distintivos efetiva-se, nas sílabas pretônicas, entre os segmentos médios abertos e fechados tanto na série anterior quanto na posterior. Tal padrão se comprova em palavras como "pesar" e "morar", cujas pronúncias abertas ou fechadas das vogais ( $[\mathrm{\varepsilon}]$ sar ou p[e]sar e $\mathrm{m}[\mathrm{o}] \mathrm{rar}$ ou $\mathrm{m}[\mathrm{o}] \mathrm{rar}$, respectivamente) não implicam mudança de sentido, como ocorre em contexto tônico: são apenas variantes de um mesmo elemento fonológico, os chamados arquifonemas /E/ e/O/. Note-se, no entanto, que, esses quatro segmentos - $[\mathrm{e}],[\varepsilon],[0]$ e $[0]$ - podem ocorrer na fala constituindo marcas dialetais e coatuando, a depender do ambiente linguístico, com as vogais altas. Essa última possibilidade, classificada como alçamento ou alteamento e facilmente verificável em todos os dialetos do $\mathrm{PB}$, culmina em uma neutralização esporádica entre vogais médias e altas, conhecida como debordamento.

Por apresentar distintas motivações e/ou restrições a depender do indivíduo, da situação comunicativa, da comunidade de fala e do item lexical, dessa temática ocuparam-se, numa perspectiva quer fonética, quer fonológica, Camara Jr. (1970, 1977), Bisol (1981, 2003), Yacovenco (1993), Callou et al. (1986, 1991), Cardoso (1999), Silva (1991), Brandão; Cruz (2005), Marques (2006), dentre vá-

2 A descrição completa dos fatores e justificativas que presidem a cada uma dessas variáveis encontra-se em Rocha (2013, p. 90-103) 
rios outros. A maioria dessas abordagens enfatiza a atuação dos processos de harmonização e de redução vocálicas. No primeiro caso, a presença de uma vogal alta tônica sucedendo a pretônica motivaria a elevação. Por outro lado, na redução, "as vogais se tornam articulatoriamente mais próximas dos segmentos consonantais adjacentes", pois integram um ambiente fonológico em que "não há, na palavra, vogal alta que possa desencadear o processo de alçamento" (CARMO, 2009, p. 24).

Embora esses parâmetros sejam legítimos, eles não atingem todos os casos presentes nos mais variados dialetos de nosso país. Alguns estudos (cf. VIEGAS, 2001; OLIVEIRA, 2008; LEE; OLIVEIRA, 2003; e ROCHA, 2013) ilustram uma realidade linguística bastante peculiar: existem itens lexicais, em que, mesmo diante de fatores condicionantes propícios ao alçamento, as pretônicas, em alguns dialetos ou idioletos, não se concretizam como altas. Em contrapartida, há vocábulos cujo contexto linguístico é, aparentemente, a ele desfavorável e se legitima o processo na prática. Interpretando-os, Oliveira $(2008$, p. 10) afirma:

devemos 'situar' a variação sonora nos itens lexicais. Em outras palavras, estou assumindo o modelo da difusão lexical e propondo que dialetos diferentes propagam os processos sonoros de maneira diferenciada pelo léxico. (...) a montagem da forma fonética do léxico é individual, muito embora os mecanismos acionados sejam os mesmos.

Como se verifica, a questão é complexa, merecendo por isso ser investigada mais a fundo, o que, além de contribuir para o conhecimento da dinâmica dos falares, neste caso, de um recorte do falar fluminense, pode ainda concorrer para a discussão de questões teóricas mais amplas, em especial as que dizem respeito à implementação das mudanças segundo um modelo neogramático ou um modelo difusionista.

\subsection{A Sociolinguística Variacionista}

Esta pesquisa norteou-se pelos pressupostos teórico-metodológicos da Sociolinguística Variacionista ou Teoria da Variação e Mudança, proposta por Weinreich, Labov e Herzog (1968) e consolidada pelos estudos de Labov na década de 1970. Trata-se de uma corrente que parte do princípio de que a variação e a mudança resultam da atuação de fatores linguísticos e extralinguísticos, relacionando diretamente heterogeneidade social e heterogeneidade linguística. Baseando sua análise na comunidade de fala, a mencionada corrente conclui que, apesar de as variantes, presentes na realidade dialetal e individual, pareçam desordenadas, elas são previstas pelo Sistema e, portanto, intrínsecas à língua. Enquanto metodologia, a Sociolinguística prioriza, enfim, dentre outros aspectos, a 
aliança entre escolha de informantes representativos de realidades significativas e um contexto de entrevista favorável a manifestações linguísticas com alto grau de naturalidade.

Segundo Labov, a seleção dos informantes se dá de forma aleatória, porém estratificada. A organização dos dados se efetiva em células que ilustram variáveis sociais, sendo compostas minimamente por cinco indivíduos cada. Tal fato permite que qualquer fenômeno linguístico estudado seja interpretado como um conjunto de manifestações reais, das quais o falante e/ou a comunidade de fala dispõem. Demonstra, ainda, que a opção entre as muitas variantes existentes resulta da interferência direta de aspectos estruturais (o contexto linguístico em que se situa o segmento analisado) e sociais (fatores extralinguísticos, tais como faixa etária, sexo, grau de escolaridade, grau de formalidade, etc.). No que se refere à interferência desses últimos fatores, merece destaque a faixa etária dos informantes por sua relevância no estudo da relação entre variação e mudança em curso, já que algumas variantes podem coatuar infinitamente sem ocasionarem mudança, enquanto a generalização de uma delas resulta em uma alteração sistemática. Como essa mudança não ocorre aleatoriamente e evolui de maneira contínua entre indivíduos de distintas faixas etárias, a investigação de diferentes gerações pode prever no presente uma mudança efetiva no futuro que atingirá toda a comunidade de fala.

Outro aspecto extralinguístico de suma relevância para o processo investigativo aqui descrito é o chamado grau de formalidade do discurso. Segundo Labov, ele se divide basicamente em fala monitorada e fala casual e deve ser um pressuposto para a proposta de entrevista do documentador. A primeira apresenta-se como resultado de um inquérito formal, em que o falante está ciente de que se trata de uma entrevista e dos objetivos desse processo. Por outro lado, a fala casual é entendida como o melhor ambiente para as observações linguísticas por apresentar-se minimamente preocupada com padrões oratórios.

Dessa forma, respeitando axiomas como a heterogeneidade ordenada da língua, as realidades social do indivíduo e contextual do segmento, o grau de formalidade do discurso, a presença de dados coerentes e consistentes, dentre outros, a Sociolinguística se caracteriza como um dos métodos atuais mais sólidos para estudos linguísticos, como será observado na análise dos dados a seguir.

\section{ANÁLISE DOS DADOS}

Foram encontrados no corpus analisado, 7.701 ocorrências de pretônica /o/. Como ilustra a Tabela 1, esses dados distribuem-se por quatro variantes distintas: a alta, as médias alta e baixa e a ditongada, respectivamente: 
Tabela 1 Distribuição das ocorrências pelas variantes de /o/ em Nova Iguaçu.

\begin{tabular}{|c|c|c|}
\hline VARIANTE & 0CO. & $\%$ \\
\hline$[\mathrm{u}]$ & 1.885 & $\mathbf{2 4 . 5}$ \\
\hline$[\mathrm{o}]$ & 5.314 & $\mathbf{6 9}$ \\
\hline$[0]$ & 81 & 1.1 \\
\hline$[\mathrm{ow}]$ & 421 & 5.5 \\
\hline
\end{tabular}

Com a centralização da análise no alçamento e na manutenção, o corpus se reduziu a 7.199 , dados, sendo $84 \%$ de [o] e $16 \%$ de [u], aproximadamente:

Tabela 2 Distribuição das ocorrências pelas variantes média fechada e alta de /o/ em Nova Iguaçu.

\begin{tabular}{|c|c|c|}
\hline VARIANTE & OCO. & $\%$ \\
\hline$[\mathrm{u}]$ & 1.885 & 16.4 \\
\hline$[\mathrm{o}]$ & 5.314 & 83.6 \\
\hline
\end{tabular}

Equiparando-se a outras abordagens sobre o tema no PB, formularam-se as hipóteses de que sílabas de ataque vazio fossem mais favoráveis à retenção das médias (cf. BRANDÃO; SANTOS; ROCHA, 2012), em contraste com os casos de contexto de hiato em que a elevação seria a regra preferida (cf. BRANDÃO; ROCHA, 2015). As tabelas a seguir confirmam tais hipóteses, já que a análise do modo e ponto de articulação da consoante precedente à vogal alvo indica o ataque vazio como ambiente propício à pronúncia [o]. Em contrapartida, a observação dos tipos de sílaba comprova a preferência por [u], em hiato, no dialeto.

Tabela 3 Distribuição das ocorrências de manutenção e de alçamento de /o/, por tipo de sílaba, na fala de Nova Iguaçu.

\begin{tabular}{|l|c|c|c|c|}
\hline \multirow{2}{*}{ TIPO DE SÍLABA } & \multicolumn{2}{|c|}{ [U] } & \multicolumn{2}{c|}{ [0] } \\
\cline { 2 - 5 } & OCO. & $\%$ & 0co. & $\%$ \\
\hline Travada por /S/ & 35 & 17.3 & 166 & 82.2 \\
\hline Travada por /N/ & 94 & 8.9 & 544 & 51.6 \\
\hline Travada por /R/ & 894 & $\mathbf{6 4 . 1}$ & 489 & 35.1 \\
\hline Sem travamento & 756 & 15.4 & 4.091 & 83.2 \\
\hline Sem travamento em contexto de hiato & 106 & $\mathbf{8 0 . 9}$ & 24 & 18.3 \\
\hline
\end{tabular}


Embora o contexto de travamento por / R/ também tenha se destacado, apresentando $64 \%$ das ocorrências com a vogal posterior alçada, cogitou-se a alta frequência do vocábulo "porque" como elemento que interfere nos resultados, sendo mais conveniente a eliminação desse item na análise final. De igual modo, os vocábulos "comigo/contigo" e "você" foram retirados da amostra, já que no primeiro grupo verificou-se a incidência da pronúncia $[u]$, enquanto no segundo a retenção de timbre foi semicategórica:

Tabela 4 Distribuição das ocorrências de elevação e manutenção de timbre, de acordo com o item analisado em Nova Iguaçu.

\begin{tabular}{|c|c|c|c|c|}
\hline \multirow{2}{*}{ ITEM } & \multicolumn{2}{|c|}{ [U] } & \multicolumn{2}{|c|}{ [0] } \\
\hline & oco. & $\%$ & oco. & $\%$ \\
\hline Porque & 840 & 99.2 & 7 & 0.8 \\
\hline Comigo/contigo & 50 & 94.3 & 3 & 5.7 \\
\hline Você & 0.6 & 7 & 1.252 & 99.4 \\
\hline
\end{tabular}

Essas subtrações resultam em mudanças consideráveis, posto que a amostra final restringe-se a 4.248 ocorrências de vogal média recuada, das quais apenas 874 , isto é, $\mathbf{2 0 . 6 \%}$ correspondem à variante alçada:

Tabela 5 Distribuição das ocorrências de vogal /o/ por variante considerada em Nova Iguaçu.

\begin{tabular}{|c|c|c|}
\hline PRETÔNICA POSTERIOR & OcO. & $\%$ \\
\hline$[\mathrm{u}]$ & 874 & 20.6 \\
\hline$[0]$ & 3.374 & 79.4 \\
\hline
\end{tabular}

A partir dessas alterações, efetuaram-se algumas rodadas no programa de análise estatísticas Goldvarb X. O Quadro 1 apresenta as características da rodada selecionada, enfatizando os fatores motivadores do alçamento da pretônica em destaque. Todas essas variáveis serão, por ordem de relevância, comentadas nas seções futuras. 
Quadro 1 Rodada selecionada para /o/.

Pretônica /o/
Qualidade da vogal da sílaba seguinte
Modo de articulação da consoante precedente
Modo de articulação da consoante seguinte
Tipo de sílaba
Distância entre a vogal alvo e outra alta na palavra
Classe gramatical do vocábulo
Escolaridade
Ponto de articulação da consoante precedente
Ponto de articulação da consoante seguinte
Sexo
Nasalidade da vogal alvo
Input: .09 Significância: $\mathbf{0 . 0 4 4}$

\section{a) Qualidade da vogal da sílaba seguinte}

A qualidade da vogal contígua à média posterior foi selecionada como elemento mais determinante para o alçamento. Efetuadas as devidas recodificações nesse grupo, os dados se redistribuíram, mediante a tonicidade e a altura da vogal contígua, como enfatiza a Tabela 6.

Tabela 6 Índices de alçamento de /o/, de acordo com o tipo de vogal contígua em Nova Iguaçu.

\begin{tabular}{|c|c|c|c|c|c|}
\hline & & \multicolumn{2}{|c|}{ [U] } & \multirow{2}{*}{ P. R. } & \multirow[b]{2}{*}{ TOTAL } \\
\hline & & $\%$ & oco. & & \\
\hline \multirow{3}{*}{ Vogal tônica (oral/nasal/nasalizada) } & [u] & 20.3 & 27 & .57 & 133 \\
\hline & [i] & 66.8 & 348 & .91 & 521 \\
\hline & 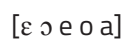 & 12 & 240 & .33 & 1.992 \\
\hline \multirow{3}{*}{ Vogal átona (oral/ nasal/ nasalizada) } & {$[u]$} & 8.7 & 27 & .43 & 309 \\
\hline & [i] & 18.5 & 72 & .62 & 390 \\
\hline & 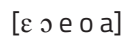 & 17.7 & 160 & .51 & 903 \\
\hline
\end{tabular}

Embora a vogal $[\mathrm{u}]$ acentuada também favoreça a aplicação da regra (.57), os pesos relativos e índices percentuais corroboram a defesa de que [i] seja mais influente já que o alçamento de /o/ é mais provável em contextos em que, suceden- 
do a vogal alvo, se encontra a tônica alta não homorgânica (.91) ou um segmento átono equivalente (.62). Em contrapartida, a manutenção de timbre é mais provável se, após a vogal átona, existe uma tônica não alta, já que o menor peso lhe foi atribuído, quando o fator de referência é o alçamento.

Percebe-se, assim, a influência do processo de harmonização vocálica, uma vez que a assimilação de traços de altura se apresenta tanto na retenção das médias, quanto na sua elevação.

\section{b) Modo de articulação da consoante precedente}

O segundo elemento mais relevante para a mudança sonora de /o/ é o modo de articulação da consoante precedente. Remetendo ao processo de redução vocálica, esse fator se alia às demais características articulatórias dos sons adjacentes à vogal alvo, visando ao estabelecimento de relações de assimilação entre os traços consonantais e vocálicos.

Tabela 7 Índices de alçamento de /o/, de acordo com o modo de articulação da consoante precedente em Nova Iguaçu.

\begin{tabular}{|l|c|c|c|c|}
\hline \multirow{2}{*}{$\begin{array}{c}\text { MODO DE ARTICULAÇÃo } \\
\text { (CONTEXTO PRECEDENTE) }\end{array}$} & \multicolumn{2}{|c|}{ [U] } & \multirow{2}{*}{ P. R. } & TOTAL \\
\cline { 2 - 5 } & $\%$ & 0co. & & \\
\hline Oclusivas & $\mathbf{2 8 . 3}$ & 724 & $\mathbf{. 6 4}$ & 2.559 \\
\hline Fricativas & $\mathbf{1 5 . 7}$ & 87 & $\mathbf{. 5 7}$ & 553 \\
\hline Líquidas (laterais e vibrantes) & 3 & 22 & .13 & 740 \\
\hline Nasal & 10.4 & 41 & .38 & 396 \\
\hline
\end{tabular}

Embora todos os percentuais apresentados na tabela anteriormente indiquem, em maior ou menor grau, o predomínio da variante média, a comparação entre os diferentes modos demonstra que, na fala de Nova Iguaçu, consoantes oclusivas $(28.3 \%)$ e fricativas $(15.7 \%)$ foram menos resistentes. Em consonância com esses percentuais, os pesos relativos sugerem que, no ataque da sílaba de núcleo pretônico, oclusivas (.64) e fricativas (.57) favoreçam a elevação, enquanto segmentos nasais e líquidos inibem a aplicação da regra.

\section{c) Modo de articulação da consoante seguinte à vogal alvo}

À semelhança do supracitado, o modo de articulação da consoante seguinte à vogal alvo foi igualmente postulado com o objetivo de avaliar a atuação da re- 
dução vocálica no recorte de fala observado. Os dados de Nova Iguaçu indicam que, uma vez descartadas as ocorrências de segmentos africados em que tendencialmente o alçamento derivaria da harmonização vocálica com uma alta não homorgânica, os maiores índices de elevação correspondem, respectivamente, a segmentos nasais (.63) e fricativos (.55). Em contrapartida, a manutenção é mais frequente, em presença de segmentos líquidos (.41) e oclusivos (.43).

Tabela 8 Índices de alçamento e manutenção de /o/, de acordo com o modo de articulação da consoante seguinte em Nova Iguaçu.

\begin{tabular}{|l|c|c|c|c|}
\hline \multirow{2}{*}{ MODO DE ARTICULAÇÃo (CONTEXTO SEGUINTE) } & \multicolumn{2}{|c|}{ [U] } & \multirow{2}{*}{ P. R. } & \multirow{2}{*}{ TOTAL } \\
\cline { 2 - 5 } & $\%$ & $\mathbf{0 C O}$ & & \\
\hline Oclusiva & 10.6 & 162 & .43 & 1.523 \\
\hline Fricativa & $\mathbf{2 0 . 3}$ & 210 & $\mathbf{. 5 5}$ & 1.035 \\
\hline Líquidas (laterais e vibrantes) & 19.2 & 136 & .41 & 709 \\
\hline Nasal & $\mathbf{3 6 . 9}$ & 317 & $\mathbf{. 6 3}$ & 859 \\
\hline
\end{tabular}

\section{d) Tipo de sílaba}

O tipo de sílaba em que a pretônica se situa também se mostrou relevante para a aplicação da regra de elevação da média recuada na fala de Nova Iguaçu. Essa variável focalizou, inicialmente, diferentes possibilidades de preenchimento de coda, sendo passível de alterações no decurso da investigação. Eliminados os dados de contexto de hiato e as ocorrências do vocábulo "porque", o alçamento se mostra pouco frequente atingindo seu limite máximo em presença de /S/ (30.7\%), ambiente apontado como principal motivador da aplicação da regra (.71), sendo sucedido apenas pela coda vazia seguida por consoante (.54).

Tabela 9 Índices de alçamento de /o/, de acordo com o tipo de sílaba em Nova Iguaçu.

\begin{tabular}{|l|c|c|c|c|c|c|}
\hline \multirow{2}{*}{ TIPO DE SÍLABA } & \multicolumn{2}{|c|}{ [0] } & \multicolumn{2}{c|}{ [U] } & \multirow{2}{*}{ P. R. } & \multirow{2}{*}{ TOTAL } \\
\cline { 2 - 6 } & $\%$ & 0co. & $\%$ & 0co. & & \\
\hline /S/ & 69.3 & 79 & $\mathbf{3 0 . 7}$ & 35 &. $\mathbf{7 1}$ & 114 \\
\hline /N/ & 85.7 & 544 & 14.3 & 91 & .45 & 635 \\
\hline /R/ & 89.3 & 458 & 10.7 & 55 & .26 & 513 \\
\hline Ausência de travamento & 76.8 & 2.293 & $\mathbf{2 3 . 2}$ & 693 & $\mathbf{. 5 4}$ & 2.986 \\
\hline
\end{tabular}


Apesar de se reconhecer a legitimidade desses condicionamentos, considera-se viável avaliar a coatuação de fatores, sobretudo a concomitante presença de um segmento alto sucedendo a vogal em questão. Acredita-se que a análise das ocorrências que compõem esses grupos possa indicar a atuação paralela de outros contextos, reduzindo a importância das relações de assimilação entre vogais e consoantes na amostra.

\section{e) Distância entre a vogal alvo e outra alta presente na palavra}

A distância entre a pretônica média e uma vogal alta tônica ou átona presente no vocábulo também se mostrou relevante para o alçamento de /o/. Como ressalta a tabela a seguir, essa variável dialoga com a natureza da vogal da sílaba seguinte, já que é justamente em presença de um segmento alto tônico e contíguo que prevaleceu a variante alta $[\mathrm{u}]$ (58.5). De maneira equivalente, é esse ambiente o mais propenso à elevação de /o/ (.59). Enquanto em presença de vogais altas não contíguas tônicas (.37) ou átonas (.18), a manutenção é mais provável, uma pretônica alta contígua se mostrou neutra (.50) quando a referência é o alçamento de $/ \mathrm{o} /$.

Tabela 10 Índices de alçamento e manutenção de /o/, de acordo com a distância entre a pretônica e outra vogal alta da palavra em Nova Iguaçu.

\begin{tabular}{|l|l|c|c|c|c|}
\hline \multicolumn{2}{|c|}{ DISTÂNCIA DE OUTRA VOGAL ALTA } & \multicolumn{2}{c|}{ [U] } & \multirow{2}{*}{ P. R. } & \multirow{2}{*}{ TOTAL } \\
\cline { 3 - 5 } & Contígua & $\%$ & 0co. & & \\
\hline \multirow{2}{*}{ Tônica } & Não contígua & 58.5 & 369 & .59 & 631 \\
\hline \multirow{2}{*}{ Átona } & Contígua & 11.1 & 21 & .37 & 189 \\
\cline { 2 - 6 } & Não contígua & 13.6 & 92 & .50 & 674 \\
\hline
\end{tabular}

\section{f) Classe gramatical do vocábulo}

A classe gramatical do vocábulo em que a pretônica se apresenta foi selecionada como o sexto grupo favorável à elevação de /o/. Cumpre enfatizar, no entanto, que, apesar da baixa produtividade da variante [u], a distribuição dos percentuais varia, sendo os numerais $(48 \%)$, as conjunções $(33.3 \%)$ e as formas finitas dos verbos $(29.1 \%)$, respectivamente, os elementos mais alçados. De maneira equivalente, os pesos relativos $(.93, .85$ e .55 , respectivamente) sugerem essas mesmas classes como mais suscetíveis à aplicação da regra de elevação. 
Tabela 11 Îndices de alçamento de /o/, de acordo com a classe dos vocábulos em Nova Iguaçu.

\begin{tabular}{|l|c|c|c|c|}
\hline \multirow{2}{*}{ CLASSES DE VOCÁBULLOS } & \multicolumn{2}{|c|}{ [U] } & \multirow{2}{*}{ P. R. } & \multirow{2}{*}{ TOTAL } \\
\cline { 2 - 5 } & $\%$ & 0CO. & & \\
\hline Nomes & 18.1 & 571 & .48 & 3.162 \\
\hline Advérbios & 10 & 1 & .31 & 10 \\
\hline Conjunções & $\mathbf{3 3 . 3}$ & 2 & $\mathbf{. 8 5}$ & 6 \\
\hline Numerais & $\mathbf{4 8}$ & 12 & .93 & 25 \\
\hline Verbos - formas finitas & $\mathbf{2 9 . 1}$ & 270 & $\mathbf{. 5 5}$ & 928 \\
\hline
\end{tabular}

Como indica a Tabela 11, conjunções e numerais com a vogal posterior foram pouco frequentes na amostra. Das 4.248 ocorrências descritas na análise final, somente 24 são classificadas como numerais e 6 como conjunções. Com o objetivo de avaliar a interferência de um mesmo item ou contexto nos comportamentos encontrados, as tabelas 12 e 13 descrevem os vocábulos que se apresentaram em cada um desses grupos:

Tabela 12 Ocorrências de alçamento e manutenção de /o/ em numerais, de acordo com o item lexical em que a vogal alvo se apresenta.

\begin{tabular}{|l|c|c|}
\hline \multirow{2}{*}{\multicolumn{2}{|c|}{ ITEM LEXICAL }} & \multicolumn{2}{|c|}{ OCORRÊNCIAS } \\
\cline { 2 - 3 } & [U] & [0] \\
\hline Oitocentos & 10 & \\
\hline Quatrocentos & 2 & 13 \\
\hline Noventa & & \\
\hline
\end{tabular}

Tabela 13 Ocorrências de alçamento e manutenção de /o/ em conjunções, de acordo com o item lexical em que a vogal alvo se apresenta.

\begin{tabular}{|c|c|c|}
\hline \multirow{2}{*}{ ITEM LEXICAL } & \multicolumn{2}{|c|}{ OCORRÊNCIAS } \\
\hline & [U] & [0] \\
\hline Portanto & 1 & \\
\hline Porém & & 3 \\
\hline Conforme & 1 & 1 \\
\hline
\end{tabular}


Os 25 numerais em que a pretônica /o/ se apresenta correspondem a apenas três itens distintos: "oitocentos", "quatrocentos" e "noventa". Os casos de alçamento se distribuem nos dois primeiros vocábulos (oitocentos e quatrocentos), em que a variante $[\mathrm{u}]$ foi categórica na amostra. Acredita-se que, em "quatrocentos" e "oitocentos" se esteja preservando na média pretônica o timbre alto original postônico dos vocábulos "quatro" e "oito". Em "noventa", a variante média abarca as 12 ocorrências encontradas. Trata-se de uma átona eventual, derivada da palavra "n[0]ve", contexto considerado potencialmente mais resistente à elevação (cf. BISOL, 1981).

Embora o número de conjunções seja bem mais reduzido, comportamentos categóricos também se efetivam. Os seis dados encontrados se distribuem entre os itens "conforme" (2), "porém" (3) e "portanto" (1). Como se verifica, a conjunção adversativa "porém" equivale à metade das ocorrências dessa variável, tendo por comportamento categórico a manutenção. Em contrapartida, a palavra "conforme" se mostrou variável, ora com a variante média, ora com a elevada, enquanto a única ocorrência de "portanto" teve a pretônica alçada na fala de Nova Iguaçu.

De igual modo, no que tange às formas finitas dos verbos, a frequência de um mesmo item ou contexto também influenciou na qualidade dos resultados (cf. ROCHA, 2013). No entanto, em virtude do maior número de dados, não foi possível elucidá-los neste artigo.

\section{g) Escolaridade}

Embora a escolaridade tenha sido classificada como o sétimo fator relevante para o alçamento de /o/, trata-se da primeira característica social ressaltada na análise. Seu controle visava a avaliar o prestígio das variantes estudadas no dialeto analisado.

Em linhas gerais, estudos sobre o mesmo fenômeno em distintos dialetos comprovam que, independentemente da formação intelectual do entrevistado, a manutenção de timbre médio é a preferência na maior parte dos dialetos do PB. A Tabela 14 confirma a variante [o] como mais prestigiada, posto que, na fala de indivíduos menos escolarizados, o emprego da variante alta $(24.9 \%)$ foi mais presente e é mais provável (.58), em contraste com os de nível de escolaridade mais elevado. Embora os índices de aplicação descritos não sejam muito expressivos, parecem corroborar a hipótese de que a variante alta da vogal posterior seja mais estigmatizada do que a média no PB, já que na oralidade de sujeitos potencialmente menos cultos a tendência à elevação é maior ao passo que na fala de sujeitos mais cultos o oposto se verifica. 
Tabela 14 Índices de alçamento e manutenção de /o/, de acordo com a Escolaridade dos informantes em Nova Iguaçu.

\begin{tabular}{|l|c|c|c|c|}
\hline \multirow{2}{*}{ ESCOLARIDADE DOS INFORMANTES } & \multicolumn{2}{|c|}{ [U] } & \multirow{2}{*}{ P. R. } & \multirow{2}{*}{ TOTAL } \\
\cline { 2 - 4 } & $\%$ & 0co. & & \\
\hline Ensino Fundamental (2 segmento) & $\mathbf{2 4 . 9}$ & 56 & $\mathbf{. 5 8}$ & 1.430 \\
\hline Ensino Médio & 19.6 & 25 & .49 & 1.148 \\
\hline Ensino Superior & 17.5 & 93 & .44 & 1.670 \\
\hline
\end{tabular}

Não se pode, por fim, desprezar o tipo de inquérito de que derivam os dados. Em se tratando de diálogos entre um documentador e um informante, em que os entrevistados têm consciência das gravações, embora ignorem seus propósitos reais, acredita-se que o predomínio da variante média em um contexto de razoável monitoramento possa estar relacionado ao seu maior prestígio social na fala de Nova Iguaçu.

\section{h) Ponto de articulação da consoante precedente à vogal alvo}

Em consonância com as análises sobre a relação entre o processo de redução vocálica e o fenômeno do alçamento de /o/ foram, também, observados os pontos de articulação dos segmentos adjacentes, tendo se destacado tanto a consoante atuante no ataque pretônico, quanto aquelas presentes na sílaba subsequente, como se mostra neste e no próximo item. Após as devidas recodificações, os pontos labial, alveolar, alveopalatal, palatal e velar foram recodificados em coronais e não coronais.

Os índices expressos na Tabela 15 indicam que, na fala de Nova Iguaçu, as vogais posteriores precedidas por consoantes [-coronais] se destacaram na amostra não só como o ambiente mais favorável à aplicação da regra (.55), mas também com o maior percentual de ocorrências de alçamento $(24.8 \%)$, ao passo que segmentos [+coronais] precedendo a vogal alvo parecem motivar sua preservação como média [o].

Tabela 15 Índices de alçamento de /o/, de acordo com ponto de articulação da consoante precedente em Nova Iguaçu.

\begin{tabular}{|l|c|c|c|c|}
\hline \multirow{2}{*}{$\begin{array}{c}\text { PONTO DE ARTICULAÇÃo } \\
\text { (CONTEXTO PRECEDENTE) }\end{array}$} & \multicolumn{2}{|c|}{ [U] } & \multirow{2}{*}{ P. R. } & \multirow{2}{*}{ TOTAL } \\
\cline { 2 - 4 } & $\%$ & $\mathbf{0 C O}$ & & \\
\hline [+ Coronal] (alveolares, alveopalatais e palatais) & 12.1 & 171 & .40 & 1.412 \\
\hline [- Coronal] (labiais e velares) & $\mathbf{2 4 . 8}$ & 703 & $\mathbf{. 5 5}$ & 2.836 \\
\hline
\end{tabular}




\section{i) Ponto de articulação da consoante seguinte à vogal alvo}

Semelhantemente ao supracitado, o ponto de articulação da consoante presente no ataque da sílaba subsequente à vogal pretônica foi selecionado dentre os elementos que presidem à implementação da variante [u] em Nova Iguaçu. $\mathrm{Na}$ amostra de fala em questão, percebe- se que os dados de alçamento foram escassos. No entanto, consoantes [-coronais] (.57) se apresentam como mais favoráveis ao processo, que atingiu $21.2 \%$ das ocorrências.

Tabela 16 Índices de alçamento de /o/, de acordo com o ponto de articulação da consoante seguinte em Nova Iguaçu.

\begin{tabular}{|l|l|l|l|l|}
\hline \multirow{2}{*}{ PONTO DE ARTICULAÇÃo (CONTEXTO SEGUINTE) } & \multicolumn{2}{|c|}{ [U] } & \multirow{2}{*}{ P. R. } & \multirow{2}{*}{ TOTAL } \\
\cline { 2 - 4 } & \multicolumn{1}{|c|}{$\%$} & \multicolumn{1}{|c|}{ OCO. } & & \\
\hline [+ Coronal] (alveolares, alveopalatais e palatais) & 20 & 479 & .45 & 2.398 \\
\hline [- Coronal] (labiais e velares) & $\mathbf{2 1 . 2}$ & 392 & $\mathbf{. 5 7}$ & 1.847 \\
\hline
\end{tabular}

\section{j) Sexo/Gênero}

O penúltimo fator relevante para a pronúncia alta $[\mathrm{u}]$ na amostra observada foi o sexo dos informantes. Em consonância com a escolaridade, esse fator foi inicialmente postulado entre as demais características sociais dos entrevistados, a fim de avaliar a presença de estigmas em relação às variantes da vogal pretônica. Mais especificamente, abordagens de cunho sociolinguístico incluem no perfil dos informantes o sexo/gênero, partindo do pressuposto de que, a depender da avaliação social da variante, homens são mais suscetíveis à mudança sonora do que as mulheres. Além disso, a adequação à norma de prestígio costuma ser mais saliente na fala feminina em contraste com a masculina. Mesmo sendo evidente a baixíssima produtividade da variante alta em ambos os sexos em Nova Iguaçu, a tabela a seguir demonstra que o alçamento foi mais frequente no discurso de informantes do sexo masculino $(22.4 \%)$, sendo esse fator mais sujeito à aplicação da regra (.54).

Tabela 17 Índices de alçamento de /o/, de acordo com o sexo/gênero dos informantes em Nova Iguaçu.

\begin{tabular}{|c|c|c|c|c|}
\hline \multirow{2}{*}{ SEXO/GÊNERO DOS INFORMANTES } & \multicolumn{2}{|c|}{ [U] } & \multirow{2}{*}{ P. R. } & \multirow{2}{*}{ TOTAL } \\
\hline & $\%$ & oco. & & \\
\hline Masculino & 2.4 & 450 & 54 & 2.011 \\
\hline Feminino & 9 & 424 & 46 & 2.237 \\
\hline
\end{tabular}


Em suma, ainda que os pesos relativos descritos anteriormente sejam pouco expressivos aproximando-se consideravelmente da neutralidade, eles não só sugerem o prestígio linguístico da pronúncia média, em contraste com a alta, no dialeto em questão, como também colaboram com a hipótese de que a variante alta posterior seja mais estigmatizada no $\mathrm{PB}$.

\section{k) Nasalidade da vogal alvo}

Por fim, destaca-se a nasalidade da vogal alvo, como último fator relevante para a aplicação da regra de elevação de /o/, na fala de Nova Iguaçu. Em consonância com grande parte dos fatores descritos nessa seção, os percentuais relativos a esse grupo fortalecem a defesa de que a pronúncia [o] é a preferência no PB. A baixíssima produtividade da variante $[\mathrm{u}]$ em contextos de travamento nasal reitera o defendido em Camara Jr., (1970), Callou; Leite (1986), Battisti (1993), dentre outros que constam da Bibliografia deste estudo. No entanto, não anula a relevância da nasalidade sobre o alçamento, já que os pesos relativos sugerem vogais nasalizadas (.62) como mais suscetíveis à elevação, enquanto segmentos orais se aproximam consideravelmente da neutralidade.

Tabela 18 Índices de alçamento de /o/, de acordo com a Nasalidade da vogal alvo em Nova Iguaçu.

\begin{tabular}{|l|c|c|c|c|}
\hline \multirow{2}{*}{ NASALIDADE DA VOGAL PRETÔNICA } & \multicolumn{2}{|c|}{ [U] } & \multirow{2}{*}{ P. R. } & \multirow{2}{*}{ TOTAL } \\
\cline { 2 - 5 } & $\%$ & 0co. & & \\
\hline Oral & $\mathbf{8 . 9}$ & 601 & $\mathbf{. 5 1}$ & 3.176 \\
\hline Nasal & 4.2 & 90 & .35 & 635 \\
\hline Nasalizada & $\mathbf{1 . 9}$ & 183 & $\mathbf{. 6 2}$ & 437 \\
\hline
\end{tabular}

\section{CONSIDERAÇÕES FINAIS}

Conforme o exposto na seção anterior, da análise dos dados depreende-se, ao mesmo tempo, um baixo índice geral de aplicação da regra (.09) e uma diversidade de condicionamentos, presidindo ao alçamento. Poucos fatores, contudo, apresentaram índices expressivos, distanciando-se, significativamente, da neutralidade. Dentre outras possibilidades, a contiguidade como a vogal alta [i] se destacou. Além disso, considerou-se a recorrência de um mesmo item como importante para a qualidade de alguns resultados. Acredita-se que comportamentos semelhantes possam ter influenciado outros fatores selecionados. Em outras palavras, sugere-se não só a interferência do léxico, mas também a coatuação de condicionamentos no corpus investigado. 
Deve-se levar em conta, ainda, o fato de estarem reunidos dados que, embora sujeitos ao alteamento, correspondem à atuação de duas regras distintas, a de harmonização e a de redução, o que, naturalmente, implica a seleção de um maior número de variáveis. Acredita-se que a análise de cada regra em particular possa deixar mais claros os condicionamentos e inputs de cada uma delas, o que, por questões de tempo, não foi possível fazer no presente estudo.

Apesar de se reconhecer a maior influência de fatores linguísticos na análise do fenômeno em pauta, optou-se por não desprezar o perfil dos entrevistados. Nesse sentido, se destacaram, nessa ordem, a escolaridade e o sexo dos informantes. A comparação entre os dados expressos nas tabelas 14 e 17 (cf. seção 3, itens g e j, respectivamente) e àqueles ilustrados na tabela adiante sobre a faixa etária, confirma a evidente preferência pela manutenção e a proximidade percentual entre os fatores. No que tange à escolaridade, a Tabela 14 comprovou que, o alçamento de /o/ é inversamente proporcional à formação dos entrevistados, decrescendo à medida que se eleva o nível de escolaridade. No que concerne ao sexo dos entrevistados, a Tabela 17 demonstrou que [u] é mais frequente na fala masculina. Por fim, os índices descritos na Tabela 19 demonstram que indivíduos mais jovens são mais resistentes ao alçamento.

Tabela 19 Índices de alçamento de /o/, de acordo com a faixa etária dos informantes em Nova Iguaçu.

\begin{tabular}{|l|c|c|c|}
\hline \multirow{2}{*}{ FAIXA ETÁRIA } & \multicolumn{2}{|c|}{ [U] } & \multirow{2}{*}{ TOTAL } \\
\cline { 2 - 4 } & $\%$ & 0Co. & \\
\hline $\mathbf{2 5}-\mathbf{3 5}$ anos & 18.8 & 219 & 1.167 \\
\hline $\mathbf{3 6}-\mathbf{5} \mathbf{5}$ anos & $\mathbf{2 0 . 9}$ & 327 & 1.565 \\
\hline $\mathbf{5 6}-\mathbf{7 5}$ anos & $\mathbf{2 1 . 6}$ & 328 & 1.516 \\
\hline
\end{tabular}

Em suma, este estudo permite afirmar que o dialeto investigado se situa na chamada "área de falar fluminense" (cf. DIAS, 2008, p. 284). À semelhança de outros dialetos do Sudeste do Brasil, o comportamento da vogal pretônica /o/ em Nova Iguaçu se distribui, nessa ordem, entre as regras de manutenção, alçamento e abaixamento e, consequentemente, se aproxima dos falares do centro de Minas Gerais (DIAS, 2008), do noroeste de São Paulo (SILVEIRA, 2008; CARMO, 2009) e de outras áreas do Estado do Rio de Janeiro (SILVA, 1995; YACOVENCO, 1993). 


\section{REFERÊNCIAS BIBLIOGRÁFICAS}

BATTISTI, Elisa. Elevação das vogais médias pretônicas em sílaba inicial de vocábulo na fala gaúcha. 1993. Dissertação (Mestrado em Letras Vernáculas) - Instituto de Letras, Universidade Federal do Rio Grande do Sul, Porto Alegre, 1993.

BISOL, Leda. Harmonização vocálica: uma regra variável. 1981. Tese (Doutorado em Linguística) - Faculdade de Letras, Universidade Federal do Rio de Janeiro, Rio de Janeiro, 1981.

Neutralização das átonas. Revista D.E.L.T.A, vol. 19:2, p. 267-276, 2003.

BRANDÃO, Silvia Figueiredo; CRUZ, Maria Luiza Carvalho. Um estudo contrastivo sobre as vogais médias pretônicas em falares do Amazonas e do Pará com base nos dados do ALAM e do ALISPA. In: AGUILERA, Vanderci (org.). A geolinguística no Brasil: caminhos e perspectivas. Londrina: Editora da Universidade Estadual de Londrina, 2005, p. 299-318.

BRANDÃO, Silvia Figueiredo; ROCHA, Fabiane de Mello Vianna; SANTOS, Elisa Ramalho dos. Vogais médias pretônicas em início de vocábulo na fala do Rio de Janeiro. Letras \& Letras (Online), v. 28, p. 273-278, 2012.

BRANDÃO, Silvia Figueiredo; ROCHA, Fabiane de Mello Vianna. Vogais médias pretônicas na fala da região sudeste: um panorama geo-sociolinguístico. Signum: Estudos da Linguagem, v. 18, p. 333-364, 2015.

CALLOU, Dinah; LEITE, Yonne. As vogais pretônicas no falar carioca. Estudos linguísticos e literários, Salvador, 5, p. 151-162, 1986.

; LEITE, Yonne; COUTINHO, Lilian. Elevação e abaixamento das vogais pretônicas no Rio de Janeiro. Organon, Porto Alegre, 18, p. 71-78, 1991.

CAMARA JR., Joaquim Mattoso. Estrutura da Lingua Portuguesa. Rio de Janeiro: Vozes, 1970.

. Para o estudo da fonêmica portuguesa. Rio de Janeiro: Padrão, 1977.

CARDOSO, Suzana. As vogais pretônicas no Brasil: uma visão diatópica. In: AGUILERA, Vanderci (org.). Português no Brasil: estudos fonéticos e fonológicos. Londrina: Editora da UEL, 1999, p. 93- 124.

CARMO, Márcia Cristina do. As vogais médias pretônicas dos verbos na fala culta do interior paulista. 2009. Dissertação (Mestrado em Linguística). Universidade Estadual Paulista, 2009.

DIAS, Melina Rezende. A variação das vogais médias pretônicas no falar dos mineiros de Piranga e de Ouro Branco, 2008. Dissertação (Mestrado em Estudos Linguísticos) Faculdade de Letras, Universidade Federal de Minas Gerais, 2008.

LABOV, William. Sociolinguistics patterns. Oxford: Blackwell, 1972. 1994.

. Principles of linguistic change. v. 1: Internal factors. Cambridge, Blackwell, 
. Principles of linguistic change. v. 2: Social factors. Cambridge, Blackwell, 2001.

LEE, Seung Hwa; OLIVEIRA, Marco Antonio de. Variação inter-e-intra-dialetal no Português brasileiro: um problema para a teoria fonológica. In: HORA, Demerval; COLLISCHONN, Gisela (org.). Teoria linguística, fonologia e outros temas. João Pessoa: Editora Universitária, 2003, p. 67-91.

MAIA, Vera Lúcia. Vogais pretônicas médias na fala de Natal. Estudos Linguísticos e Literários, Salvador, 5, p. 209-226, 1986.

MARQUES, Sandra Maria Oliveira. As vogais médias pretônicas em situação de contato dialetal, 2006. Tese (Doutorado em Letras Vernáculas) - Faculdade de Letras, Universidade Federal do Rio de Janeiro, Rio de Janeiro, 2006.

OLIVEIRA, Marco Antonio. Variação Fonológica: O indivíduo e a comunidade de fala. VIII Seminário de Pesquisa do PPGLLP-Unesp-Araraquara. (Seminário), 2008.

ROCHA, Fabiane de Mello Vianna. O comportamento das vogais médias pretônicas na fala de Nova Iguaçu-RJ. 2013. Dissertação (Mestrado em Letras Vernáculas) - Faculdade de Letras, Universidade Federal do Rio de Janeiro, Rio de Janeiro, 2013.

SILVA, Myrian Barbosa da. Um traço regional na fala culta de Salvador. Organon, Porto Alegre, 18, p. 79-89, 1991.

SILVA, Edila Vianna. Uma contribuição para o conhecimento do Português no Brasil: as pretônicas fluminenses. In: Miscelânea de estudos linguísticos, filológicos e literários in memoriam Celso Cunha. Rio de Janeiro: Nova Fronteira, 1995, p. 391-397.

VIEGAS, M do C. O alçamento de vogais médias pretônicas e os itens lexicais. 2001. Tese (Doutorado) - Faculdade de Letras, Universidade Federal de Minas Gerais, Belo Horizonte, 2001.

WEINREICH, Uriel; LABOV, William; HERZOG, Marvin. Empirical foundations for a theory of language change. In: LEHMANN, W; MALKIEL, Y. (eds.). Directions for historical linguistics. Austin: University of Texas Press, 1968, p. 97-195.

YACOVENCO, Lilian Coutinho. As vogais médias pretônicas no falar culto carioca. 1993. Dissertação (Mestrado em Língua Portuguesa) - Universidade Federal do Rio de Janeiro, Rio de Janeiro, 1993. 